\title{
Studying the clinical encounter with the Adaptive Leadership framework
}

This article was published in the following Dove Press journal:

Journal of Healthcare Leadership

22 August 2012

Number of times this article has been viewed

\section{Donald E Bailey Jr' ${ }^{1,2}$ \\ Sharron L Docherty' \\ Judith A Adams' \\ Dana L Carthron ${ }^{3}$ \\ Kirsten Corazzini ${ }^{1,2}$ \\ Jennifer R Day' \\ Elizabeth Neglia' \\ Marcus Thygeson ${ }^{4}$ \\ Ruth A Anderson ${ }^{1,2}$}

'School of Nursing, Duke University, ${ }^{2}$ Center for the Study of Aging and Human Development, Duke University,

Durham, NC, ${ }^{3}$ School of Health

Science, Division of Nursing, Winston

Salem State University, Winston

Salem, NC, ${ }^{4}$ Medical Services, Blue

Shield of California, San Francisco, CA, USA
Correspondence: Donald E Bailey Jr School of Nursing, Duke University, DUMC, PO Box 3322, Durham, NC 27710 , USA

$\mathrm{Tel}+19196813003$

Fax +19196818899

Email chip.bailey@duke.edu
Abstract: In this paper we discuss the concept of leadership as a personal capability, not contingent on one's position in a hierarchy. This type of leadership allows us to reframe both the care-giving and organizational roles of nurses and other front-line clinical staff. Little research has been done to explore what leadership means at the point of care, particularly in reference to the relationship between health care practitioners and patients and their family caregivers. The Adaptive Leadership framework, based on complexity science theory, provides a useful lens to explore practitioners' leadership behaviors at the point of care. This framework proposes that there are two broad categories of challenges that patients face: technical and adaptive. Whereas technical challenges are addressed with technical solutions that are delivered by practitioners, adaptive challenges require the patient (or family member) to adjust to a new situation and to do the work of adapting, learning, and behavior change. Adaptive leadership is the work that practitioners do to mobilize and support patients to do the adaptive work. The purpose of this paper is to describe this framework and demonstrate its application to nursing research. We demonstrate the framework's utility with five exemplars of nursing research problems that range from the individual to the system levels. The framework has the potential to guide researchers to ask new questions and to gain new insights into how practitioners interact with patients at the point of care to increase the patient's ability to tackle challenging problems and improve their own health care outcomes. It is a potentially powerful framework for developing and testing a new generation of interventions to address complex issues by harnessing and learning about the adaptive capabilities of patients within their life contexts.

Keywords: nursing, patient care, providers, health care practitioners, patient centered care, nursing providers, complex adaptive systems

\section{Overview and background}

Many view "leadership" in health care organizations as referring or relating to the behavior of only the top administrators. ${ }^{1}$ This view erodes the central meaning of leadership and ignores the capacity for leadership at the point of care. Top administrators and managers, for example, may or may not display effective leadership in their approach to accomplishing organizational goals; instead, they may merely be "exercising authority." 2 To paraphrase Williams, ${ }^{3}$ real leadership is about increasing other people's own ability to tackle difficult problems. By this definition, leadership is something that people do (it is a behavior) not a position or job title; and it helps other people solve difficult problems - something that is highly relevant to clinical care.

In this paper we wish to draw attention to the verb root, "to lead," and in so doing, we will argue that leadership is a behavior that anyone in a system can display. As a verb, "lead" is defined as "showing the way for others either by example or by promoting a 
better way."4 Leading is not confined to top administrators and managers, and is not contingent on personal traits or styles. ${ }^{5}$ Leadership can be relationship focused, such as in transformational leadership, or non-relationship focused, such as in transactional leadership. ${ }^{6}$ Leadership emerges in day to day work as people interact with each other to do their jobs. ${ }^{7,8}$ When emergent leadership behaviors are not actively suppressed by those in authority, leadership can truly improve the capacity of health care practitioners to influence better care outcomes for patients. ${ }^{2,9}$ Recognizing that leadership is a personal capability that is not contingent on one's position in a hierarchy, it allows us to reframe both the care-giving and organizational roles of nurses and other front-line clinical staff. This reframed view of leadership suggests new avenues for research to describe and explicate the value of leadership, and how it is operationalized by practitioners at the point of care.

Many scholars and practitioners now view nursing and health care organizations as complex adaptive systems. ${ }^{10-12}$ In this view, organizations are comprised of a diverse group of people who, within the context of the formal social and organizational structures in which they live and work, interact spontaneously as needed to accomplish the task at hand in a process called self-organization. Self-organization is a process by which people reciprocally change their behaviors to adapt to the demands of the environment - in this case the clinical situation. ${ }^{13}$ Through their interactions, people (or in this case, health care practitioners [HCPs]), create the norms and structures needed to be successful. Some of these become long-standing patterns and others are fleeting; however, there is continual evolution (ie, adaptation) as people interact with each other and their environment. Through these processes, the properties of the system emerge, such as how patients are involved, or not involved, in their own care, or the level of quality attained in patient care. Leadership is also a property of these systems; it arises in the interactions among the system members as they adapt to new situations. Leaders emerge at all levels in an organization, not just at the top. Leadership thus appears when and where it is needed and may come from anyone in the system. ${ }^{14,15}$ For example, a front line nurse may influence a nursing unit to adopt a new care practice; a physician may influence a diabetic patient to develop new skills for monitoring blood sugar, or a patient may motivate a clinician to change their approach to communication or treatment.

Little research has been done, however, to explore what leadership means at the point of care, particularly in the relationship between health care providers and patients. Heifetz et al ${ }^{16}$ described the "adaptive leadership" framework, which explicates the role of leadership in an organizational context, in helping others adapt and move forward in difficult situations. Others have described the application of this theory in medicine. ${ }^{2,9}$ The purpose of this paper, is to (1) describe the Adaptive Leadership framework ${ }^{16}$ and how it can be used to explore health care provider leadership behaviors at the point of care; and (2) demonstrate the application of the Adaptive Leadership framework to nursing research. We propose that new knowledge is gained when this lens is applied to nursing research problems across the continuum of care.

\section{Adaptive Leadership framework}

The fundamental idea underlying the Adaptive Leadership framework can be explained by complexity science. ${ }^{11}$ Just as organizations are a complex adaptive system, so too are individuals. Individuals adapt both physically and psychologically as they interact with the environment. ${ }^{9}$ This adaptation cannot be done by a health care practitioner for a patient. This model explicitly acknowledges the adaptive "health work" that patients or their caregivers must do for themselves and emphasizes the real need for clinicians to be the type of leaders described by Williams ${ }^{3}-$ those who can increase their patient's own ability to tackle difficult problems. The Adaptive Leadership framework is a useful guide for developing, applying, and describing these leadership skills at the point of care.

The Adaptive Leadership framework proposes that there are two broad categories of challenges that patients face: technical and adaptive challenges. Technical challenges are "situations where both the problem and the potential solution can be clearly defined"9 by an expert; thus they are best addressed by technical work done by that expert, such as a clinician. In situations requiring technical work, the provider uses clinical expertise and authority to apply a solution. Adaptive challenges, on the other hand, occur in situations in which a patient must adapt to a health issue, for example by engaging in self-managing a chronic illness. In this case, the patient must do the work - the adapting, learning, and behavior change. In adaptive work, patients must re-evaluate their existing beliefs, and learn and adopt new priorities and habits related to health. This change, learning, and growth involves loss; to improve self-management, they must discard strategies that are not working, give up behaviors that are comfortable but unhealthy, and establish new ways of managing their chronic condition. ${ }^{16}$ Table 1 summarizes the differences between adaptive and technical challenges and work.

Adaptive leadership is the work providers do to mobilize and support patients and their families in doing their adaptive work. To put it in the context of Williams' description of leadership, providers engage in adaptive leadership to increase the 
Table I Technical and adaptive challenges

\begin{tabular}{|c|c|}
\hline Technical challenges & Adaptive challenges \\
\hline Simple or complicated problems. & Complex problems. \\
\hline An expert somewhere already & Solution is unknown and must \\
\hline knows the solution (a puzzle). & be discovered (a mystery). \\
\hline A technical intervention exists & No expert or technical \\
\hline or can be constructed to solve & intervention can solve the \\
\hline the problem. & problem. \\
\hline Solution does not require material & Solution requires learning \\
\hline learning and behavior change & and behavior change by the \\
\hline by the person(s) experiencing & person(s) experiencing the \\
\hline the problem. & problem. \\
\hline The challenge is addressed & The person(s) with the \\
\hline by identifying and applying & challenge must work (overcome \\
\hline the expertise and technical & resistance) to discover (learn) \\
\hline interventions required to solve & and adopt the new beliefs, \\
\hline \multirow[t]{3}{*}{ the problem (technical work). } & attitudes, and behaviors \\
\hline & required to resolve the \\
\hline & challenge (adaptive work). \\
\hline
\end{tabular}

patient's abilities to tackle their own challenges. ${ }^{3}$ It shifts our current understanding of the provider's role as being one that involves patients in their own care, ${ }^{17}$ to a model where providers and patients act together to co-produce care ${ }^{18}$ It brings to light that patients engage with the provider in his or her own care, and it also recognizes that patients bring their own knowledge and expertise to the work. Thus adaptive leadership requires a shared understanding of the patient's problem, resources, and learning together to find solutions. Patients manage their health in the context of their life circumstances and adaptive leadership strategies will assist patients to effectively self-manage their illness-related problems within this life context. Adaptive leadership involves problem solving with the patient and family and perhaps connecting the patient with other patients in the same situation, so that the patient can learn from the experience of others with similar problems.

The Adaptive Leadership framework provides a useful way to organize what occurs during patient-provider encounters, including the delivery of care on hospital inpatient units, in nursing homes, and in other clinical settings where patients and providers interact for the purpose of co-producing improved health for the patient. Exploring technical work, adaptive work, and adaptive leadership as set forth in this framework will provide new information about how technical clinical care and individualized adaptive care are integrated to enhance self-management. Practitioners are trained to do (and typically do) technical work for patients; they may or may not have the knowledge to support the adaptive work that patients possess to tackle an adaptive challenge. Technical problems are those that can be solved through the knowledge and skills of the providers. Adaptive challenges have solutions that do not inherently lie with the providers, but instead require the adaptive leadership skills of providers to support the development of solutions by patients. ${ }^{19}$ For example, a nurse can deliver an emergent bronchodilator to the patient with chronic asthma who is having difficulty breathing, but he/she cannot ensure that the patient avoids the social situations in which he/she is exposed to second-hand smoke. Most health challenges require elements of both technical and adaptive work.

Because most patients engage in self-management strategies as they undergo treatment and experience its side effects, the adaptive work patients do each day may have a greater impact on health outcomes than the technical work of providers. Heifetz et a $1^{16}$ point out that one of the most common leadership errors is to try to address adaptive challenges with technical interventions. In health care, over-reliance on technical interventions can undermine, distract, or interfere with patients doing their adaptive work. For example, overreliance on medications can prevent patients from doing the appropriate adaptive work to learn how to manage minor discomfort and anxiety without relying on medication. That may expose them to unnecessary risk of drug side effects, possible dependence and addiction, and may deprive them of experiencing the benefits of self-mastery. The Adaptive Leadership framework, while new to health care, helps organize concepts and guides providers in supporting patients in doing adaptive work; it also encourages providers to avoid overusing technical interventions that may interfere with patients doing adaptive work. ${ }^{9}$ Adaptive Leadership does not supplant other models of self-management, but it may be viewed as the next step in organizing existing midrange cognitive behavioral theories and opening areas of developing new midrange theories.

Mid-range theories in nursing and medicine have addressed how patients' self-manage their care and how HCPs should interact with patients to facilitate the management of chronic health conditions. For example, the Common Sense Model of Chronic Illness Management ${ }^{20}$ provides a theory about how to understand patients' representations of their illness and symptoms, and to link these to actions in self-management. Response shift theory and transformative learning theory provide two theoretical explanations about how patients with chronic illness reframe their situations to learn and grow as a result of chronic illness. ${ }^{21}$ Cognitive behavioral theories describe the continual adaptation process in chronic illness and how practitioner interventions may help to shape behavior changes over time. ${ }^{22}$ The framework of shared decision-making describes how HCPs and patients negotiate decision-making in a collaborative manner, which is in contrast to a paternalistic or informed consent 
approach, which involves one-sided decision-making. ${ }^{23}$ This framework distinguishes between problem-solving, which is the role of the physician, and decision-making, which is negotiated by both parties being informed of the treatment options and the values of the patient. ${ }^{24}$ What these theories lack is a way to conceptualize and define the relationship between HCPs and patients and the work each must do to facilitate patients' development and adaptation to chronic illness.

The Adaptive Leadership framework provides a novel lens through which research questions regarding nursing practice as "leadership at the point of care" can be systematically and comprehensively viewed. The framework can be used to facilitate conceptualization of the research problem, and may be used in the generation of research questions or hypotheses. It may be helpful in identifying new substantively important predictors and outcomes, and may also be a useful framework for developing a new generation of interventions at the point of care. Studies that apply the Adaptive Leadership framework to research on the care process may create important knowledge about how patient-provider interactions can synergistically produce short and long term changes in the health of individuals and populations.

The components of the Adaptive Leadership framework are enacted via interpersonal behavioral interactions (both verbal and non-verbal), and are, for the most part, abstract or qualitative. To properly study these concepts we need to develop clear, generally accepted definitions, and valid and reliable metrics that enable us to distinguish between adaptive and technical challenges and work. We need also to identify and measure different adaptive leadership behaviors as well as different components, types, and aspects of adaptive work. It is critical that the metrics developed measure concepts that are clearly defined and substantively important.

One approach to developing these metrics is paradigm case formulation (PCF) and parametric analysis (PA), which have been applied successfully to other emerging health care domains and difficult to define concepts, such as patientcentered medical homes, palliative care, and collaborative care. ${ }^{25-27}$ The PCF process defines a case and demonstrates similarities, differences, and acceptable variations. ${ }^{25}$ This process begins with developing a consensus description of a paradigm case - a case of the phenomenon that has all the possible, as well as quintessential characteristics of the phenomenon. ${ }^{26}$ One might say of a paradigm case of Adaptive Leadership, "if there was ever a case of Adaptive Leadership, this is it." ${ }^{26,27}$ Once the paradigm case of Adaptive Leadership has been described, the next step is to describe the range of transformations that this paradigm case could take while still being considered a case of Adaptive Leadership. ${ }^{26}$ For example, if the paradigm case identified the health care worker as a physician, an allowable transformation might be "any member of the health care team." Identifying allowable transformations defines the boundaries of, and the allowable types of variation in, the set of cases that comprise the phenomenon of interest.

Once a paradigm case is defined and the allowable transformations are identified, these transformations are then parameterized using parametric analysis. Each allowable transformation represents a dimension or variable that can be used to measure the differences between cases of the phenomenon. ${ }^{26}$ Parametric analysis identifies the parameters that will be used to measure meaningful variations in the allowable transformations in cases of the phenomenon. ${ }^{26}$ The PCF and PA processes can be done by an individual, but in practice they generally have been applied in a facilitated group setting. Together they are an explicit method for developing the conceptual clarity and shared understanding required to transfer knowledge to a community of independent researchers who will engage in the empirical study of novel phenomena. ${ }^{25}$

Candidate parameters for inclusion in the PCF and PA formulation of adaptive leadership include the balance of adaptive and technical components in a health challenge (ranging from purely adaptive, to a blend, to purely technical); the adaptive capacity of the patient (related to their psychosocial strengths, health beliefs, and level of patient activation); the provider's skill with adaptive leadership; and the quality and strength of the provider-patient relationship because the strength of the "holding environment," or the space formed by their relationship, strongly influences the potential amount and pace of adaptive work. Likewise, pre-empiric work, such as creating clear definitions and measurement parameters for new conceptual fields, is needed to more fully characterize adaptive leadership behaviors in clinical practice so they can be recognized and quantified. In the section that follows we propose some Adaptive Leadership research exemplars. Operationalizing these exemplars will require doing important work to develop standard definitions and approaches for measuring concepts related to the Adaptive Leadership framework.

\section{Adaptive Leadership: research exemplars}

Scholars at Duke University School of Nursing are using the Adaptive Leadership framework to examine nursing research problems at the individual and system levels. We present five research exemplars here to illustrate how the framework can be instrumental in exploring the phenomenon of interest and facilitate the articulation of the research problems, questions, and hypotheses. Table 2 summarizes key components 
of each research problem as viewed through the Adaptive Leadership framework.

In this first research exemplar, Day ${ }^{28}$ explored caregiving for family members with dementia. These caregivers face many daily challenges including behavioral difficulties and aggression. To support family caregivers and to allow care recipients to remain in the home for as long as possible, it is essential for health care providers to understand the technical and adaptive challenges of caregivers, and to work together to identify technical and adaptive interventions. In a recent study exploring the challenges of caregiving, caregivers described the fatigue associated with caring for family members with dementia. One woman who was caring for her mother with dementia also worked full-time. Her mother awakened multiple times during the night, often with the need to void, requiring the caregiver's assistance. This interrupted her sleep, caused her to be listless at work, and created a level of fatigue that put the caregiver and the care recipient's health and safety at risk. To understand the adaptive work that family caregivers might do, we could ask the following research question in future research: Does teaching a family member stress management techniques reduce fatigue associated with care recipient incontinence? While the health care provider is not intervening directly with the problem of incontinence (technical work), they are teaching the caregiver ways to deal with a consequence of the incontinence - caregiver fatigue (adaptive work). Supporting this adaptation to a situation provides the caregiver a valuable tool in addressing this and possibly other challenges that may arise while caring for a family member with dementia.

In our second exemplar, Adams et $\mathrm{al}^{30}$ are examining how health care providers communicate with families about life-sustaining treatment and transitions to palliative care. One common approach treats this transition as a technical challenge by providing patients and family members with highly technical information regarding prognostic indicators, and expecting them to make difficult decisions such as whether to continue ventilator support, antibiotics, tube feeding, and other life sustaining measures. This places the family members in the position of choosing a medical treatment rather than choosing a desired outcome. ${ }^{29}$ Providers and patients often avoid these transition discussions in end-of-life care because there is no truly desired option available. One possible reason providers may avoid these transition discussions is that they may lack strategies to move beyond the technical challenges, and they may also lack the knowledge to recognize and address adaptive challenges. In the context of an inherently unclear situation where there is no desirable outcome amenable to technical expertise, the Adaptive Leadership framework could help providers in working with the patient to identify related adaptive challenges, and it might enable the provider in supporting the patient with addressing them.

Adams et $\mathrm{al}^{30}$ described a case study of family decisionmaking for a dying ICU patient in which the family faced the challenge of accepting that their loved one was not likely to survive the hospitalization, and that if he did, he would not recover a quality of life that was acceptable to him. The family was having grave difficulty coming to terms with the idea that he would not survive. Understanding this helped to reveal an important adaptive challenge the family faced: the tradeoff between continuing life support which would make the patient less comfortable, or choosing a comfort path and risking earlier death. The family expressed a strong desire to talk with the patient one last time. This raised another adaptive challenge: the tradeoff between keeping the patient comfortable or decreasing sedation in hopes of being able to talk with him, which would cause significant discomfort due to air hunger. To make these emotionally charged decisions in a way that fit the patient's goals required the family to do the adaptive work to accept the inevitability of death and develop the ability to face their grief. It also required that the providers enable or facilitate this adaptive work.

In our third exemplar, Carthron et $\mathrm{al}^{31}$ examine the trajectory of self-management activities among diabetic AfricanAmerican grandmothers raising their grandchildren. Evidence of the long-term effectiveness of current diabetes education is lacking. This may be because educational interventions have not addressed the social context in which people are selfmanaging diabetes, nor have they addressed issues of quality of life. The importance of social and cultural contexts that influence human behavior is evident in the move toward health research approaches that are socially economically based. ${ }^{32}$ Once managed in isolation, diabetes must be self-managed within the context of the patient's life $\mathrm{e}^{33}$ and their unique situations. Further, when patients perceive that a diabetes regimen does not improve quality of life or their ability to manage day-to-day activities, they are unlikely to adhere to it. In the case of African-American grandmothers who are raising their grandchildren, HCPs must address the management of the diabetes with knowledge of their social contexts and their quality of life goals. An intervention that ignores the context of raising grandchildren is of limited benefit in this population.

Although consistent use of educational materials among nurses and dieticians, as well as a diabetes education curriculum that meets the American Diabetes Association recognition requirements, ${ }^{34}$ these materials provide technical solutions (emphasis on the importance of adherence to diet and medication regimens) to technical challenges (elevated glycosylated hemoglobin). African-American grandmothers 


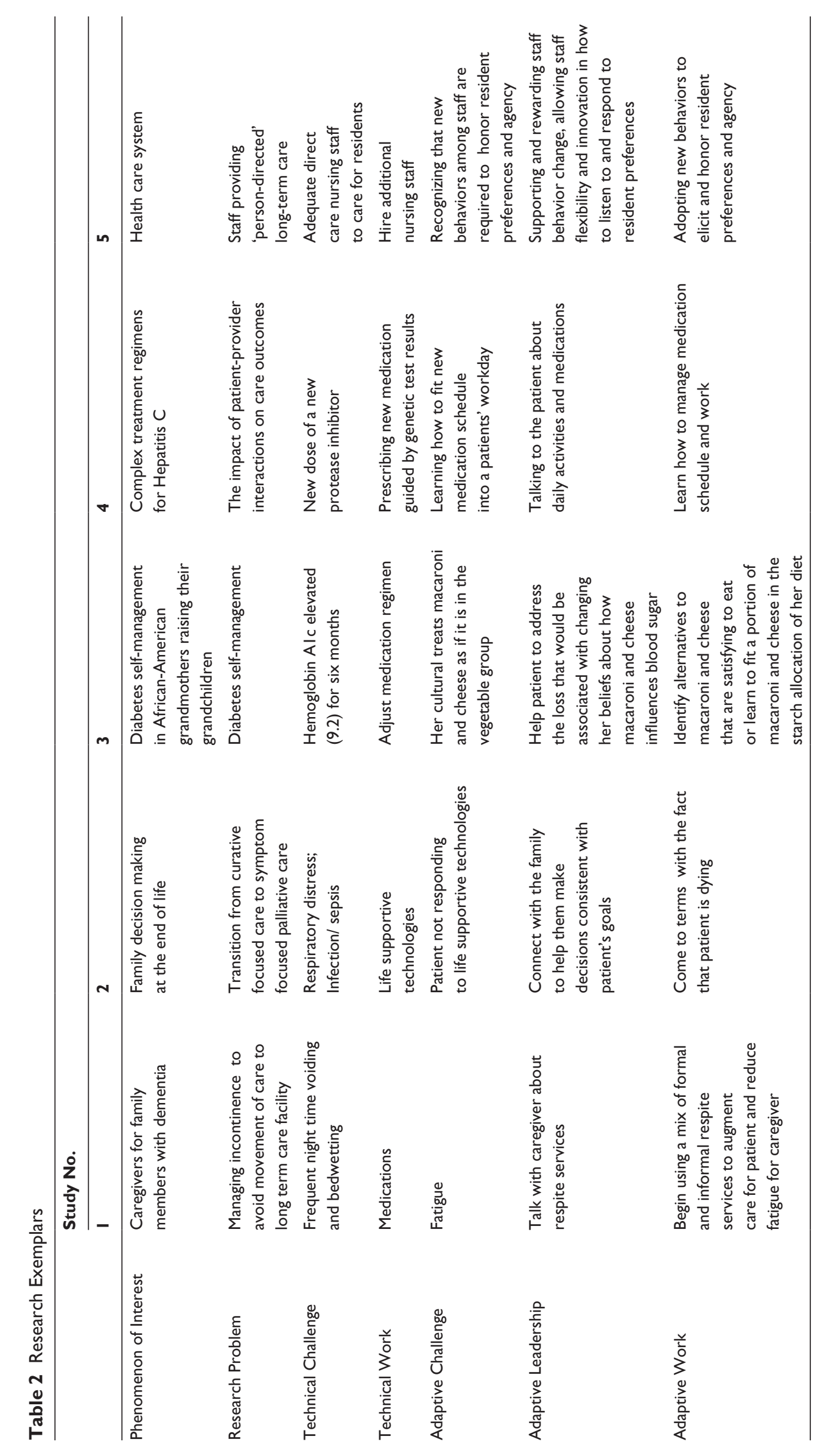


raising their grandchildren may be knowledgeable about their technical and self-management skills, as well as the resources necessary to manage their diabetes, but their priority is often not on their diabetes; instead, they face adaptive challenges related to maintaining normalcy for their grandchildren and preparing them for the future.

While the management of diabetes involves both technical and adaptive challenges and work, ${ }^{2}$ adaptive leadership techniques may provide an essential cornerstone for a new generation of self-management interventions that use technical interventions as a complement to a central focus on adaptive challenges and adaptive work. Adaptive leadership is fundamentally a non-linear, iterative, reciprocal interaction between the health care practitioner and the patient. This is in contrast to the more conventional, "linear" view of clinicianpatient interactions (do/receive). Human beings are nonlinear systems. It seems probable that non-linear approaches to care will be superior to linear approaches. Indeed linear approaches to medical management, such as sliding scale insulin, actually increase glycemic oscillations rather than stabilizing the patient. ${ }^{35}$ Using adaptive leadership techniques in the care of the diabetic patient may help us reframe and address patient management challenges more productively, rather than seeing them as unsolvable. These techniques may help patients develop their adaptive capabilities to increase their self-efficacy and ability to self-manage, so that they are globally more adaptive, resilient, and independent. ${ }^{9}$

In the fourth exemplar, Bailey et $\mathrm{al}^{36}$ are investigating how patients and health care practitioners work together to plan and initiate complex new treatment regimens for patients with chronic hepatitis $\mathrm{C}(\mathrm{CHC})$. The new $\mathrm{CHC}$ regimens are guided by a new blood test for a genetic polymorphism near the interleukin $28 \mathrm{~B}$ gene and involve treatment with two recently approved protease inhibitors that can enhance patient response to treatment and increase the probability of cure for some patients. ${ }^{37,38}$ This polymorphism is a strong predictor of treatment response for patients with genotype 1 infection, and the two protease inhibitors may cure CHC. However, the new protease inhibitors increase the complexity of the treatment and are associated with worse side effects, thereby increasing the self-management burden. With genetic test results guiding a new therapy that is expected to worsen symptoms, health care practitioner interactions with patients have an even greater potential to influence symptom trajectories and self-management. ${ }^{39}$

Successful treatment depends on patients' selfmanagement, defined as the individual's ability to engage in all aspects of illness management, including interactions with health care practitioners, sustained compliance with treatment, and management of symptoms and side effects. ${ }^{40-42}$ However, the patient-practitioner interactions needed for care in this new treatment era are uncharted. Using the Adaptive Leadership framework to explore patient-practitioner interactions in the context of new genetic test results and new therapies may enhance self-management among certain patient groups. Some potential questions are: How do patients describe their interactions with the health care practitioners? How do these interactions shape patients' perceptions of the likelihood of cure? What do patients describe as their challenges in selfmanaging? How do patients' understandings of their interactions with the practitioner promote the use of or pose barriers to symptom management during treatment? What technical work and adaptive leadership approaches do practitioners use when sharing treatment information with patients during the clinical encounter? The Adaptive Leadership framework helps us anticipate that these practitioner-patient interactions will require significant adaptive leadership on the part of the practitioner to enable adaptive work by the patient that has the potential to improve clinical outcomes.

The fifth exemplar from Corazzini et $\mathrm{al}^{43}$ relates to their research on how health care practitioners in nursing homes can transform current, institutionalized models of care to person-directed, home-like care settings through a movement known as culture change. Culture change in this context is defined as, "person-directed values and practices ... where both older adults and their caregivers are able to express choice and practice self-determination in meaningful ways at every level of daily life." ${ }^{\$ 4,45}$ To achieve these goals, practitioners in nursing homes must consider changes across multiple domains of care, ranging from the physical environment, to staffing practices, to how input from residents, families, and frontline workers is incorporated into day to day practices. It is estimated that well over $50 \%$ of nursing homes in the US are engaged in some aspects of culture change, ${ }^{46}$ and the Centers for Medicare and Medicaid Services have included culture change as part of the 'eighth scope of work' with state quality improvement organizations. ${ }^{47}$

Implementing person-directed care in culture change is an inherently adaptive challenge at a systems level given that culture change requires organizational members to give up old patterns and espouse new, normative values and behaviors congruent with person-directed care, ultimately changing the nature of the relationship of a nursing home resident with the staff and the environment. Merely following rules and procedures will not result in new caregiver values and principles; matching technical expertise to the challenge also does not solve this problem. 
In a recent focus group study, ${ }^{43}$ staff consistently described adaptive challenges such as nurse managers not seeking the knowledge of residents from other staff when planning care, and of nurse managers needing the authority to reorganize morning care routines with colleagues to accommodate resident bathing and dining preferences. By contrast, administrators identified technical challenges as barriers to change, such as not having adequate capital to purchase 'home-like' furniture. By applying our Adaptive Leadership framework, we can see that managers and administrators are in the position to facilitate the adaptive work of the front-line nursing staff. From a systems perspective, the adaptive leadership must occur across top managers to ensure that they can facilitate the adaptive work of the front-line staff necessary to develop and implement new ways of fostering person-directed care. When managers confuse adaptive challenges for technical challenges, nursing homes invest scarce resources into changes (eg, a new carpet or pictures) that do not result in fully realized person-directed care.

\section{Value added: the Adaptive Leadership framework for nursing science and research}

The Adaptive Leadership framework has the potential to explore new questions and insights about the relationships and interactions between health care practitioners, patients, and their families to increase the ability of all stakeholders in tackling challenging problems and enhancing the learning process that practitioners, patients, and families must engage in along the care trajectory. The framework draws attention to the practitioner-patient interaction, enables the development of a shared understanding of the patient's problem and resources, and proposes a model for practitioners, patients, and families to share responsibility for co-producing patientcentered approaches in improving health and care outcomes. Although we have focused our discussion on the provider as the adaptive leader, if providers and patients are truly engaged in co-producing care, it is likely that the patient and/or the family caregivers will also engage in adaptive leadership as they will facilitate changes in the provider's approaches and even the care delivery system. It is a potentially powerful framework for developing and testing a new generation of interventions to address complex issues by harnessing and learning about the adaptive capabilities of patients, families, and their providers.

Our ongoing studies highlighted in the exemplars will help us develop clear conceptual and operational definitions of terms that will distinguish between adaptive and technical challenges, and adaptive work and technical work, and describe different adaptive leadership behaviors as well as the different components, types, and aspects of adaptive work. Further, they will enable us to better understand the ways in which technical and adaptive strategies may foster and improve self-management and guide the development, testing, and delivery of new interventions to address important nursing management practice issues that have a direct impact on patients and their clinical care. By using paradigm case formulation and parametric analysis of behavioral interactions, we will develop clear descriptions of technical and adaptive challenges and work, and the adaptive leadership that occurs in the interactions between patients, family members, and practitioners. This will offer nursing science new ways of viewing the clinical encounter and the potential to improve outcomes in the context of chronic conditions and care systems issues. Reframing nursing as an opportunity to practice adaptive leadership with patients and co-workers will itself require members of the nursing community to do the adaptive work to change their culture at the point of care and in the organizations where nurses work. However, in order for patients and the health care system to recognize these benefits, nurse scholars must now begin to develop and expand upon the theory that is integrated with research, and appreciate that research programs can be an essential source of theorizing in nursing.

\section{Disclosure}

The authors report no conflicts of interest in this work.

\section{References}

1. Wilbur K. Nonviral hepatitis. J Pharm Pract. 2009;22(4):388-404.

2. Haeusler JMC. Medicine needs adaptive leadership. Physician Exec. 2010;36(2):12-15.

3. Williams D. Real Leadership: Helping People and Organizations Face Their Toughest Challenges. San Francisco, CA: Berrett-Koehler; 2005.

4. McCrimmon M. Thought Leadership [homepage on the Internet]. Ontario: Leadersdirect; [updated 2011; cited April 1, 2012.]. Available from: http:// www.leadersdirect.com/thought-leadership. Accessed April 1, 2012.

5. Steers RM, Porter LW, Bigley GA. Motivation and Leadership at Work. 6th ed. New York: McGraw-Hill; 1996.

6. Cummings GG, MacGregor T, Davey M, et al. Leadership styles and outcome patterns for the nursing workforce and work environment: A systematic review. Int J Nurs Stud. 2010;47(3):363-385.

7. Plowman DA, Solansky S, Beck TE, Baker L, Kulkarni M, Travis DV. The role of leadership in emergent, self-organization. The Leadership Quarterly. 2007;18(4):341-356.

8. Uhl-Bien M. Relational leadership theory: exploring the social processes of leadership and organizing. The Leadership Quarterly. 2006;17(6):654-676.

9. Thygeson M, Morrissey L, Ulstad V. Adaptive leadership and the practice of medicine: a complexity-based approach to reframing the doctorpatient relationship. J Eval Clin Pract. 2010;16(5):1009-1015.

10. Anderson RA, Issel LM, McDaniel Jr RR. Nursing homes as complex adaptive systems: relationship between management practice and resident outcomes. Nurs Res. Jan-Feb 2003;52(1):12-21.

11. McDaniel RR, Driebe DJ. Complexity science and health care management. In: Blair JD, Fottler MD, Savage GT, editors. Advances in Health Care Management. Vol 2. Stamford, CT: JAI Press; 2001:11-36. 
12. Begun J, White KR. The profession of nursing as a complex adaptive system: strategies for change. Research in the Sociology of Health Care. 1999;16:189-203.

13. Cilliers P. Complexity and Postmodernism: Understanding Complex Systems. London; New York: Routledge; 1998.

14. Lichtenstein BB, Uhl Bien M, Marion R, Seers A, Orton DJ, Schreiber C. Complexity leadership theory: an interactive perspective on leading in complex adaptive systems. Emergence: Complexity and Organization. 2006;8(4):2-12.

15. Uhl-Bien M, Marion R, McKelvey B. Complexity leadership theory: Shifting leadership from the industrial age to the knowledge era. The Leadership Quarterly. 2007;18(4):298-318.

16. Heifetz R, Grashow A, Linsky M. The Practice of Adaptive Leadership: Tools and Tactics for Changing Your Organization and the World. Boston, MA: Harvard Business Review Press; 2009.

17. Rise MB, Solbjør M, Lara MC, Westerlund H, Grimstad H, SteinsbekkA. Same description, different values. How service users and providers define patient and public involvement in health care. Health Expect. 2011. [Epub ahead of print.]

18. Ledema R, Sorenson R, Jorm C, Piper D. Co-producing care. In: Sorenson R, Ledema R, editors. Managing Clinical Processes in Health Services. Chatswood, NSW Australia: Elsevier Australia; 2008:105-120.

19. Heifetz RA, Linsky M. When leadership spells danger. Educational Leadership. 2004;61(7):33-37.

20. Leventhal H, Leventhal EA, Breland JY. Cognitive science speaks to the "common-sense" of chronic illness management. Ann Behav Med. Apr 2011;41(2):152-163.

21. Barclay-Goddard R, King J, Dubouloz CJ, Schwartz CE; for Response Shift Think Tank Working Group. Building on transformative learning and response shift theory to investigate health-related quality of life changes over time in individuals with chronic health conditions and disability. Arch Phys Med Rehabil. Feb 2012;93(2):214-220.

22. Pierobon A, Giardini A, Callegari S, Majani G. Psychological adjustment to a chronic illness: the contribution from cognitive behavioural treatment in a rehabilitation setting. G Ital Med Lav Ergon. Jan-Mar 2011;33(1 Suppl A): A11-A18.

23. Charles C, Gafni A, Whelan T. Decision-making in the physician-patient encounter: revisiting the shared treatment decision-making model. Soc Sci Med. Sep 1999;49(5):651-661.

24. Deber RB. Physicians in health care management: 8 . The patientphysician partnership: decision making, problem solving and the desire to participate. CMAJ. August 15, 1994;151(4):423-427.

25. Miller BF, Kessler R, Peek CJ, Kallenberg GA. Establishing the Research Agenda for Collaborative Care. Rockville, MD: Agency for Healthcare Research and Quality; 2011.

26. Peek CJ. A Collaborative Care Lexicon for Asking Practice and Research Development Questions. Rockville, MD: Agency for Healthcare Research and Quality; 2011.

27. Peek CJ, Oftedahl G. A Consensus Operational Definition of PatientCentered Medical Home (PCMH) Also Known as Health Care Home. Bloomington, MN: University of Minnesota and Institute for Clinical Systems Improvement (ICSI); 2010.

28. Day J. Compassion fatigue in informal caregivers. The Gerontologist. 2010;50(Suppl 1):106.

29. Frosch DL, Kaplan RM. Shared decision making in clinical medicine: past research and future directions. Am J Prev Med. Nov 1999;17(4): 285-294.

30. Adams JA, Bailey DE Jr, Anderson RA, Galanos AN. Adaptive leadership: a novel approach for family decision-making. J Palliat Med. 2012. In press.

Journal of Healthcare Leadership

\section{Publish your work in this journal}

The Journal of Healthcare Leadership is an international, peer-reviewed, open access journal focusing on leadership for the health profession. The journal is committed to the rapid publication of research focusing on but not limited to: Healthcare policy and law; Theoretical and practical aspects of health care delivery; Interactions between healthcare and society and evidence-based practices;
31. Carthron D, Anderson R, Bailey D. The trajectory of self-management activities among diabetic African-American caregiving grandmothers. Paper presented at the 26th Annual Meeting of the Southern Nurse Research Society, New Orleans, LA. Feb 22nd-25th, 2012.

32. Livingood W, Allegrante J, Airhihenbuwa O, et al. Applied social and behavioral science to address complex health problems. Am J Prev Med. 2011;41(5):525-553.

33. Moser A, van der Bruggen H, Widdershoven G, Spreeuwenburg C. Selfmanagement of type 2 diabetes mellitus: a qualitative investigation from the perspective of participants in a nurse-led, shared-care programme in the Netherlands. BMC Public Health. 2008;8(91):1-9.

34. Siminerio LM, Piatt GA, Emerson S, et al. Deploying the chronic care model to implement and sustain diabetes self-management training programs. Diabetes Educ. Mar-Apr 2006;32(2):253-260.

35. Wilson T, Holt T, Greenhalgh T. Complexity science: complexity and clinical care. BMJ. 2001;323(7314):685-688.

36. Bailey DE. Patient self-management and gene guided therapy for CHC. Funded grant 1R21NR013461, The National Institutes of Health/ National Institute of Nursing Research. Available at http://projectreporter. nih.gov/project_info_description.cfm?aid=8265041\&icde $=13345746 \&$ ddparam $=\& d d v a l u e=\& d d s u b=\& c r=1 \& c s b=$ default $\&$ cs $=$ ASC .2012.

37. Kwo PY, Lawitz EJ, McCone J, et al; for SPRINT-1 investigators. Efficacy of boceprevir, an NS3 protease inhibitor, in combination with peginterferon alfa- $2 b$ and ribavirin in treatment-naive patients with genotype 1 hepatitis C infection (SPRINT-1): an open-label, randomised, multicentre phase 2 trial. Lancet. August 28, 2010;376(9742):705-716.

38. Afdhal NH, McHutchison JG, Zeuzem S, et al; Pharmacogenetics and Hepatitis C Meeting Participants. Hepatitis C pharmacogenetics: state of the art in 2010. Hepatology. Jan 2011;53(1):336-345.

39. Bodenheimer T, Wagner EH, Grumbach K. Improving primary care for patients with chronic illness: the chronic care model, part 2. JAMA. 2002;288(15):1909-1914.

40. Stoller EP, Webster NJ, Blixen CE, et al. Lay management of chronic disease: a qualitative study of living with hepatitis $\mathrm{C}$ infection. Am J Health Behav. Jul-Aug 2009;33(4):376-390.

41. Audulv A, Asplund K, Norbergh KG. Who's in charge? The role of responsibility attribution in self-management among people with chronic illness. Patient Educ Couns. Oct 2010;81(1):94-100.

42. Bacon BR, Gordon SC, Lawitz E, et al; for HCV RESPOND-2 Investigators. Boceprevir for previously treated chronic HCV genotype 1 infection. N Engl J Med. March 31, 2011;364(13):1207-1217.

43. Corazzini K, Twersky J, White HK, et al. Implementing Culture Change in Nursing Homes: An Adaptive Leadership Framework. Unpublished manuscript, Duke University, Durham, NC: 2012.

44. White HK, Corazzini K, Twersky J, et al. Prioritizing culture change in nursing homes: perspectives of residents, staff, and family members. J Am Geriatr Soc. Mar 2012;60(3):525-531.

45. What is culture change? [homepage on the Internet]. Chicago: Pioneer Network; [cited December 7, 2011]. Availble from: http://www.pioneernetwork. org/CultureChange/Whatis/. Accessed December 7, 2011.

46. Doty MME, Koren MJ, Sturla EL. Culture Change in Nursing Homes: How Far Have We Come? Findings from the Commonwealth Fund 2007 National Survey of Nursing Homes. New York: Commonwealth Fund; 2008.

47. Koren MJ. Person-centered care for nursing home residents: the culturechange movement. Health Aff (Millwood). Feb 2010;29(2):312-317.

Interdisciplinary decision-making; Philosophical and ethical issues; Hazard management; Research and opinion for health leadership; Leadership assessment. The manuscript management system is completely online and includes a very quick and fair peer-review system. Visit http://www.dovepress.com/ testimonials.php to read real quotes from published authors.

\section{Dovepress}

